\title{
Cerebrospinal fluid hydrodynamic studies in children
}

\author{
HANS K:SON BLOMQUIST,* STIG SUNDIN, $†$ JAN EKSTEDT \\ From the Departments of Pediatrics* and Neurology, $\ddagger$ University of Umea, and the Department of Pediatrics, $\uparrow$ \\ University of Uppsala, Sweden
}

SUMMARY CSF-hydrodynamic investigation using the constant pressure infusion method was used in children. The CSF resting pressure was recorded and the CSF formation rate was measured. The conductance of the CSF outflow pathways and the pressure in the sagittal sinus were calculated. The method was used in children with suspicion of disturbed CSF hydrodynamics due to various neurological and other conditions. The method is applicable in paediatric neurological diagnostics and provides information for further understanding of the mechanisms behind cranial hypertension. The following mean values are offered as reference values in clinical work and in further research in this field: CSF-resting pressure $1.3 \mathrm{kPa}$, sagittal sinus pressure $1.1 \mathrm{kPa}$, pressure difference across arachnoid villi $0.5 \mathrm{kPa}$, conductance of CSF outflow pathways $22.6 \mathrm{~mm}^{3} \mathrm{kPa}^{-1} \mathrm{~s}^{-1}$, CSF formation rate $6.8 \mathrm{~m}^{3} \mathrm{~s}^{-1}$.

The physiology of the CSF has been extensively reviewed by Welch ${ }^{1}$ and the physics of the cranial cavity by Hakim et al. ${ }^{2}$ The knowledge pertaining to CSF-hydrodynamics in children is however relatively limited. Rubin et al, ${ }^{3}$ Cutler $e t a l^{4}$ and Lorenzo et $a l^{5}$ used perfusion techniques, and Katzman and Hussey, ${ }^{6}$ Bird et al, ${ }^{8}$ Di Rocco et al ${ }^{9}$ and Caldarelli et al ${ }^{10}$ used the constant rate infusion method in investigation of children with different intracranial disorders. Ekstedt ${ }^{11} 12$ introduced the constant pressure infusion method which give more data of the pressure-flow conditions of CSF than previous methods. The method has been employed in adults by Ekstedt and Fridén ${ }^{13}$ and Ekstedt. ${ }^{14}$ It has also been used in a modified version in infants by Portnoy and Croissant. ${ }^{1516}$

The aims of the present investigation were to evaluate further the constant pressure infusion method in CSF hydrodynamic studies in children, to determine the reference hydrodynamic variables and to map out some of the CSF hydrodynamic characteristics in various illnesses in children.

\section{Methods}

The fundamental features of the method are shown in fig 1 . Lumbar puncture was performed with the child sitting in the

Address for reprint requests: Dr Hans K:son Blomquist, Department of Pediatrics, University of Umeå, S-901 85 Umeå, Sweden.

Received 19 February 1985 and in revised form 25 June 1985. Accepted 27 June 1985 nurse's lap. The child was usually investigated without general analgesic or sedative medication in order not to disturb the physiological conditions but local anaesthesic was carefully injected into the skin and into the interspinal ligament before the lumbar puncture. For infants up to twelve months of age modified scalp vein needles were used. Prior to the lumbar puncture, the scalp vein needle was bent at the end to prevent insertion of cutaneous material into the lumens. The needles were joined to the connecting tubes, and needles and tubes were filled with artificial CSF. ${ }^{12}$ A suitable needle position could then be established with the aid of the analogue recorder, which operated pulse synchronously when the needle's lumen was well positioned in the subarachnoid space. One needle was in constant connection with the subarachnoidal space for measurement of the actual CSF pressure, another needle was used for infusion. Puncture was usually performed with both needles inserted into the same interspace (L3-4 or L4-5). The scalp vein needle tubes were fastened with tape on to the patient's back; the child then was carefully placed in the supine position in a specially constructed bed with a hole for the two lumbar needles in the canvas bottom. For older children disposable needles were used having a diameter of 0.7 or $0.9 \mathrm{~mm}$. From 6-7 years of age the children were placed in a specially constructed chair, changeable to a bed. ${ }^{12}$

It is of importance that no CSF is lost during insertion. Any CSF loss causes a decrease in the pressure and must, therefore, be replaced with artificial CSF. For the same reason it is also important to avoid leakage of CSF due to multiple punctures of the meninges.

For registration of the basal CSF hydrodynamic variables it is necessary that the child lies supine. The child must lie still for 3-4 hours for a complete investigation. In many cases this has not caused any problems thanks to the supine position and to the presence of nurses or parents. An 


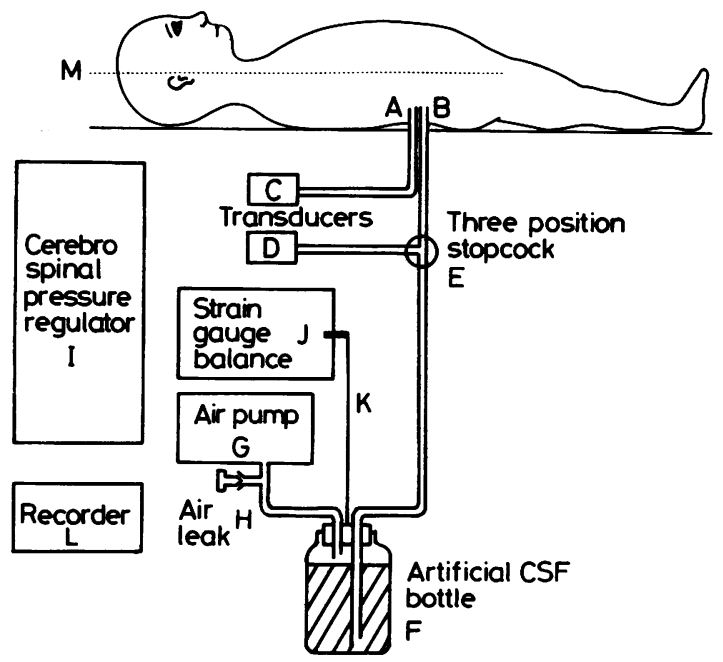

Fig 1 Experimental situation in the CSF hydrodynamic investigation. The child is lying in the supine position with two lumbar needles ( $A$ and $B$ ) in the subarachnoidal space. $A$ tube filled with artificial CSF connects the needle $A$ to a transducer $C$. The other needle, $B$, is in the same way connected to transducer $D$. An air-pressurized bottle containing artificial CSF, $F$, is connected to $B$ through a stopcock. The pressure from the airpump, $G$, is maximised through an air leak valve at $H$. The transducers $C$ or $D$ govern the cerebrospinal pressure regulator, $I$, which delivers the power to the airpump G. Flow is calculated by weighing the bottle in the strain gauge balance, $J$, in which the bottle is hanging with a fishing line, $K$. The results are given graphically with a multi-pen recorder, $L$. The reference level chosen, $M$, is the sagittal midpoint of the cranium.

investigation of this length cannot be performed in the lateral recumbent position because of inability to lay still. In some cases, the children moved too much and changes in position of the needles caused undue leakage of CSF. In these cases another examination had to be performed later.

The zero reference point was the sagittal midpoint of the skull. This corresponds fairly well with the centre of the right atrium when the patient is in the supine position.

The CSF resting pressure was recorded until a stable pressure level was reached. Usually this occurred within 30 minutes. Thereafter the bottle containing artificial CSF was connected and the pressure adjusted to about $1 \mathrm{kPa}$ above the resting pressure. The flow rate was estimated indirectly by continuously recording the weight of the bottle. When a constant pressure and flow rate was achieved after approximately 5-10 minutes the infusion pressure was increased stepwise by 0.5 or $1.0 \mathrm{kPa}$. In this way $5-8$ related pressureflow values were obtained in each investigation (fig 2 ). The slope of the regression line corresponds to the conductance of the CSF outflow pathways, that is the ease with which CSF leaves the subarachnoidal space.

Subsequently the infusion was stopped and the pressure was allowed to return spontaneously. The pre-infusion value was usually the level then attained. In some cases, when the children were still co-operative, the investigation was continued with CSF formation rate recording. By lowering the pressure in the bottle to $0.25-0.4 \mathrm{kPa}$, an outflow of CSF into the bottle was obtained (fig 3). All the CSF formed was assumed to be drained into the bottle.

Lumbar puncture is considered to be contra-indicated in some instances of increased intracranial pressure such as suspected posterior fossa mass lesions and in acute epidural haematomas. Our investigations have been done with respect to this. Cases with risk of developing herniation either have not been examined or have been investigated in collaboration with a neurosurgeon and special care has been taken in these cases just to register the pressures, not to change the existing equilibrium.

SI units have been used throughout and the following symbols are used:

$\mathbf{P}_{\text {clr }}=$ lumbar resting CSF pressure, $\mathrm{kPa}$

$\mathbf{P}_{\mathrm{ss}}=$ sagittal sinus pressure, $\mathrm{kPa}$

$\mathbf{P}_{\text {dop }}=$ pressure difference across outflow (arachnoidal villi), $\mathbf{k P a}$

$\mathrm{G}_{\mathrm{op}}=$ conductance of CSF outflow pathways, $\mathrm{mm}^{3} \mathrm{kPa}^{-1} \mathrm{~s}^{-1}$

$\mathrm{q}_{\mathrm{f}}=$ CSF formation rate, $\mathrm{mm}^{3} \mathrm{~s}^{-1}$

$1 \mathrm{kPa}=7.5 \mathrm{~mm} \mathrm{Hg}=102 \mathrm{~mm} \mathrm{H}_{2} \mathrm{O}$

$1 \mathrm{~mm}^{3} \mathrm{kPa}^{-1} \mathrm{~s}^{-1}=6 \cdot 10^{-3} \mathrm{ml}\left(\mathrm{cmH}_{2} 0\right)^{-1}=8 \cdot 10^{-3}$ $(\mathrm{mm} \mathrm{Hg})^{-1} \min ^{-1}$

\section{Material}

Three hundred and fifteen measurements were performed on 232 children with an age range of 2 days to 15 years. In 70 instances an investigation including infusion of artificial CSF was performed. In 18 children the CSF formation rate was also measured. In 245 cases recording entailed only pressure measurements.

The indication for the investigation was always suspicion of disturbed CSF hydrodynamics. Many of the children were examined several times. Some results were obtained from measurements after therapeutic procedures. The investigations were all done on clinical grounds and the parents, and when old enough the children, gave their informed consent for participation. The University Ethics Committee of Umeå approved the project.

\section{Results}

\section{The CSF hydrodynamic parameters}

The CSF pressure varied synchronously with pulse and respiration. The amplitude increased with increasing CSF pressure. When the CSF pressure was raised from 1.0 to $2.5 \mathrm{kPa}$ the amplitude increased from 0.2 to $0.5 \mathrm{kPa}$ in children with fontanelles and sutures open. In children with closed fontanelles and sutures the amplitude increased from 0.3 to $0.8 \mathrm{kPa}$ when the CSF pressure was raised in the same way. The mean between the highest and lowest amplitude was read and that value of the CSF pressure was used in the following.

In the majority of the recordings there was a linear 


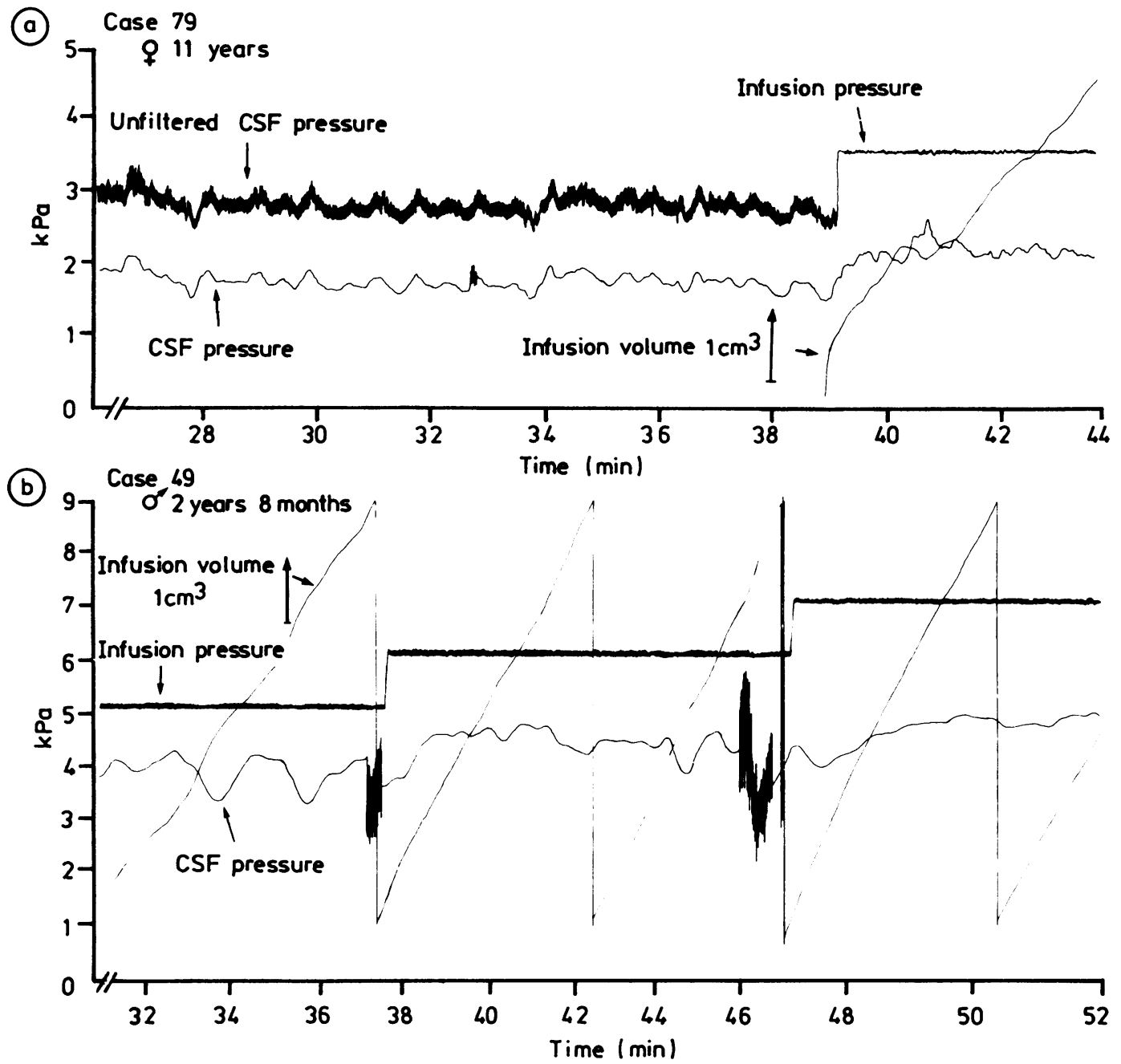

Fig 2 Parts of two actual recordings. $a$. is the end of the resting pressure period and the first few minutes of the CSF infusion. $b$. is part of another infusion at three different pressure levels. To make an analysis of the curves possible the pressure traces were separated by $1 \mathrm{kPa}$. The scale of the ordinate refers to the filtered curve. At regular intervals the unfiltered pressure was recorded to confirm an optimal needle position. When a stable resting pressure level was reached the bottle containing artificial CSF was connected and the pressure was adjusted to $1 \mathrm{kPa}$ above the resting pressure. The CSF flow rate was estimated by recording the weight of the bottle. When constant pressure and flow rate was achieved the pressure was again increased by $1 \mathrm{kPa}$ etc, until 5-8 allied pressure-flow-rate values were obtained. Note that the time axis in $b$. is altered during the third infusion period. Upward movement of the bottle weight curve means infusion of CSF into the patient.

relationship between CSF pressure and flow (fig 4). There was a linear relationship between pressure and flow also in many cases considered as pathological in their CSF hydrodynamic (fig 5).

"Normal" CSF resting-pressure $\left(\mathrm{P}_{\mathrm{clr}}\right)$. As mentioned above quite healthy children have not been examined for ethical reasons. The distribution of the CSF rest- ing pressure in 315 investigations of 232 children of various ages and with different diagnoses is shown in fig 6. Further examinations and clinical observations for several years of 18 of these children did not reveal illness that might influence CSF or blood flow. The result of the studies of these cases is summarised in table 1 . The CSF resting-pressure 5-95\% range was 


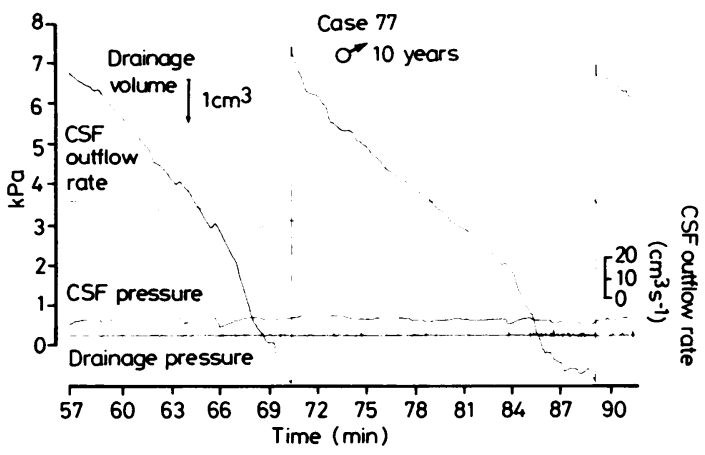

Fig 3 Part of a CSF-drainage for measurement of the CSF information rate. The drainage has been maintained for 20 minutes and the achieved pressure had stabilised at about $0.5 \mathrm{kPa}$. The CSF formation rate was calculated from the increase of the bottles weight, shown as the downward going line in the diagram.

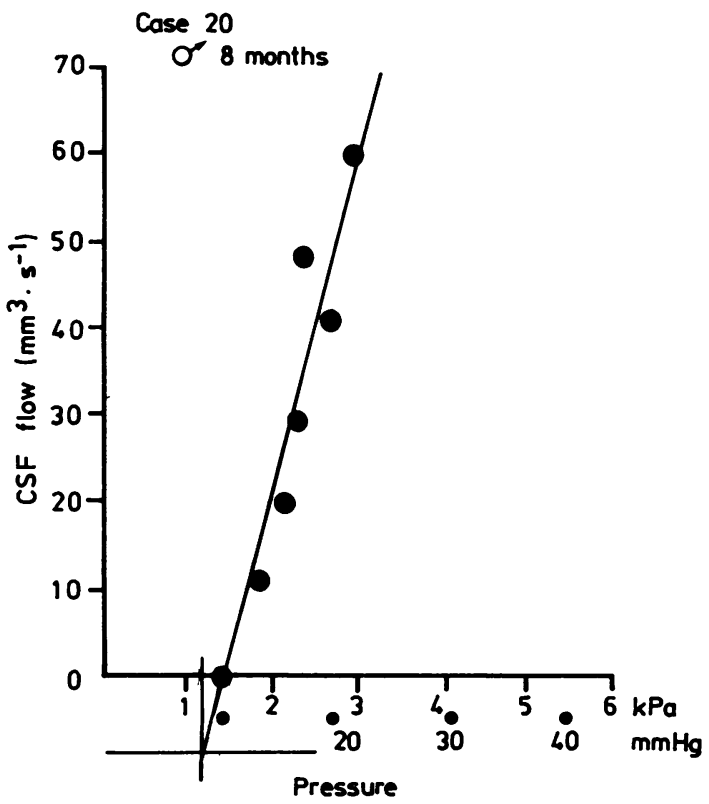

Fig 4 Pressure-flow diagram from an eight months old boy (case 20) considered to be normal as regard CSF hydrodynamics. CSF pressure on the abscissa. CSF inflow from the bottle to the subarachnoid space on the ordinate. The corresponding values were read in steady state. There is a rectilinear relation between pressure and flow. The regression line of flow on pressure that is the conductance of the CSF outflow pathways had been calculated according to the formula given in the text. The horizontal line below the abscissa represents the actual CSF formation rate. The intersection of this line and the regression line represents the artificial pressure obtained if there were no CSF formation and thus no outflow through the arachnoidal villi, that is the pressure of the CSF recipient which is mainly the sagittal sinus.
$1.0-1.6 \mathrm{kPa}$. The mean was $1.3 \mathrm{kPa}$. In the actual age interval (one month to eight years) no age dependency was seen.

Conductance of the CSF outflow pathways $\left(\mathrm{G}_{\mathrm{op}}\right)$. The distribution of 69 calculable and conceivable values for conductance of the CSF outflow pathways is shown in fig 7 . The conductance $5-95 \%$ range was 3.4-38.9 $\mathrm{mm}^{3} \mathrm{kPa}^{-1} \mathrm{~s}^{-1}$. The mean was 15.2 $\mathrm{mm}^{3} \mathrm{kPa}^{-1} \mathrm{~s}^{-1}$.

CSF formation rate $\left(\mathrm{q}_{\mathrm{f}}\right)$. The CSF formation rate was studied in 18 children between two months and 15 years of age (table 2). At a pressure level of $0.25 \mathrm{kPa}$ the registered CSF production ranged from 2.0 to $12.8 \mathrm{~mm}^{3} \mathrm{~s}^{-1}$. In one girl with a radiologically confirmed stenosis of the aqueduct a CSF formation rate of $0.8 \mathrm{~mm}^{3} \mathrm{~s}^{-1}$ was recorded. The mean value of the CSF formation rate in the other 17 investigated cases was $6.8 \mathrm{~mm}^{3} \mathrm{~s}^{-1}(5-95 \%$ within $3 \cdot 0-10 \cdot 0$ $\mathrm{mm}^{3} \mathrm{~s}^{-1}$ ).

Pressure difference across the CSF outflow pathways $\left(P_{\text {dop }}\right)$. The pressure difference across the arachnoid villi was calculated with use of the formula $P_{\text {dop }}=$ $\mathrm{q}_{\mathrm{f}} / \mathrm{G}_{\mathrm{op}}{ }^{17}$. In the 17 cases where the recorded $\mathrm{q}_{\mathrm{f}}$ can be used (see above) the $P_{\text {dop }} 5-95 \%$ range was $0 \cdot 2-1.0 \mathrm{kPa}$ and the mean $0.5 \mathrm{kPa}$ (table 2).

Sinus sagittalis pressure $\left(\mathrm{P}_{\mathrm{ss}}\right)$. The sagittal sinus pressure had in the 17 cases where $P_{\text {dop }}$ was calculable (that is cases in which $\mathrm{q}_{\mathrm{f}}$ was recorded), a mean of $1.1 \mathrm{kPa}$ (table 2).

CSF hydrodynamics in various disorders. A CSF hydrodynamic study (or a CSF resting-pressure recording) was performed when any disturbance in the CSF hydrodynamic was suspected. The exact clinical diagnosis was not always elucidated prior to the examination. The results obtained in the CSF hydrodynamic or static study thus had an influence on the final diagnosis. The usefulness of the method in confirming a particular diagnosis can, for this reason, unfortunately not be evaluated.

Communicating hydrocephalus. Ninety children with communicating hydrocephalus between 2 months and 11 years of age was examined. Thirty-nine children were examined after implantation of a shunt system. The CSF resting-pressures were in nonoperated cases and in cases without functioning shunts raised to a level of 1.9 to $3.2 \mathrm{kPa}$. The highest obtained restingpressure in patients with open fontanelles was $2.8 \mathrm{kPa}$. CSF hydrodynamic data from six investigations are given in table 3.

Spontaneously arrested hydrocephalus. Of the 90 cases with a communicating hydrocephalus 25 cases were considered probably spontaneously arrested. Most of the children had a psychomotor development within normal limits but cases with myelomeningocele, multiple congenital malformation, severe and mild psychomotor retardation were also represented. All the 

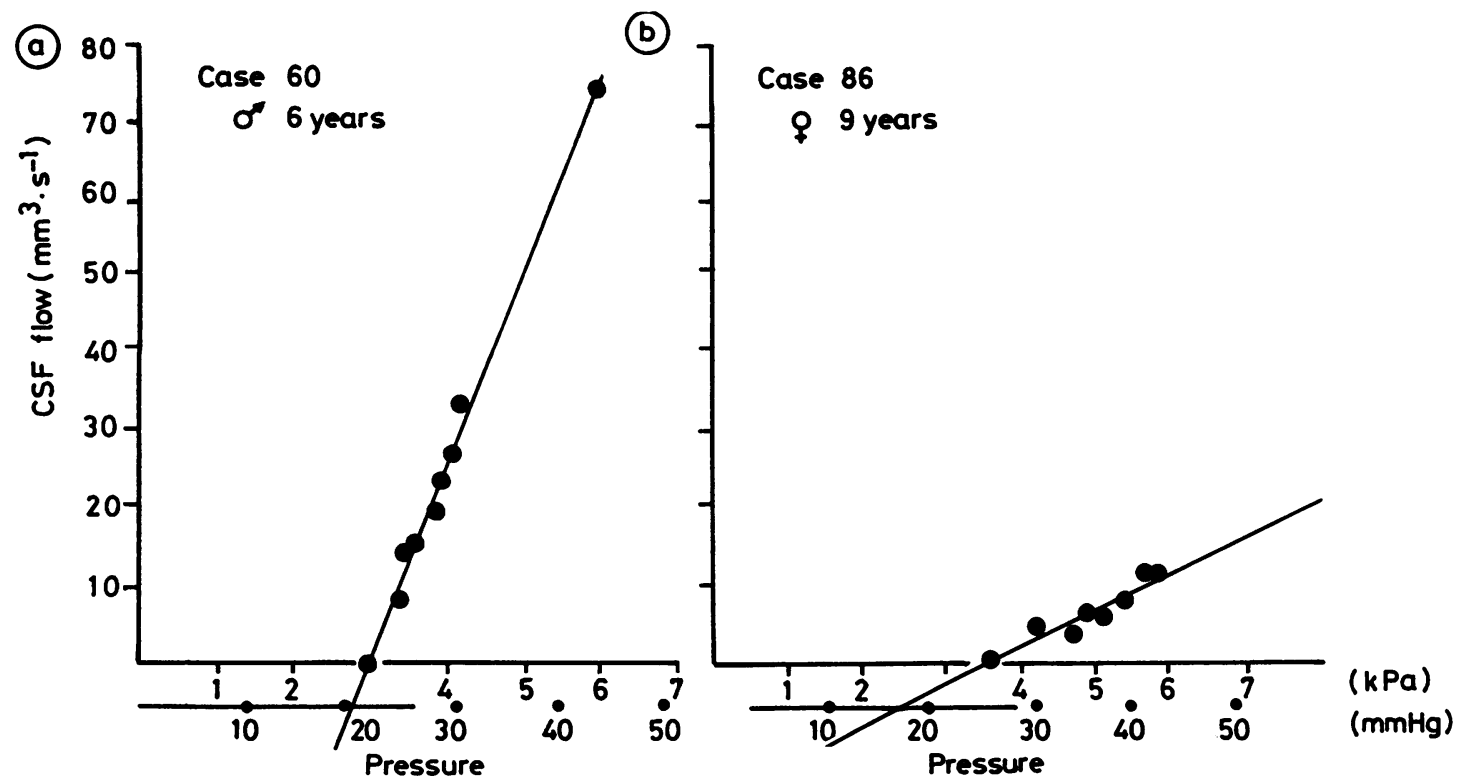

Fig 5 Pressure-flow diagrams from two children with increased CSF resting pressure. In case 60, the conductance is high, in case 86 the conductance is low, in both cases the pressures in the sagittal sinus are increased.

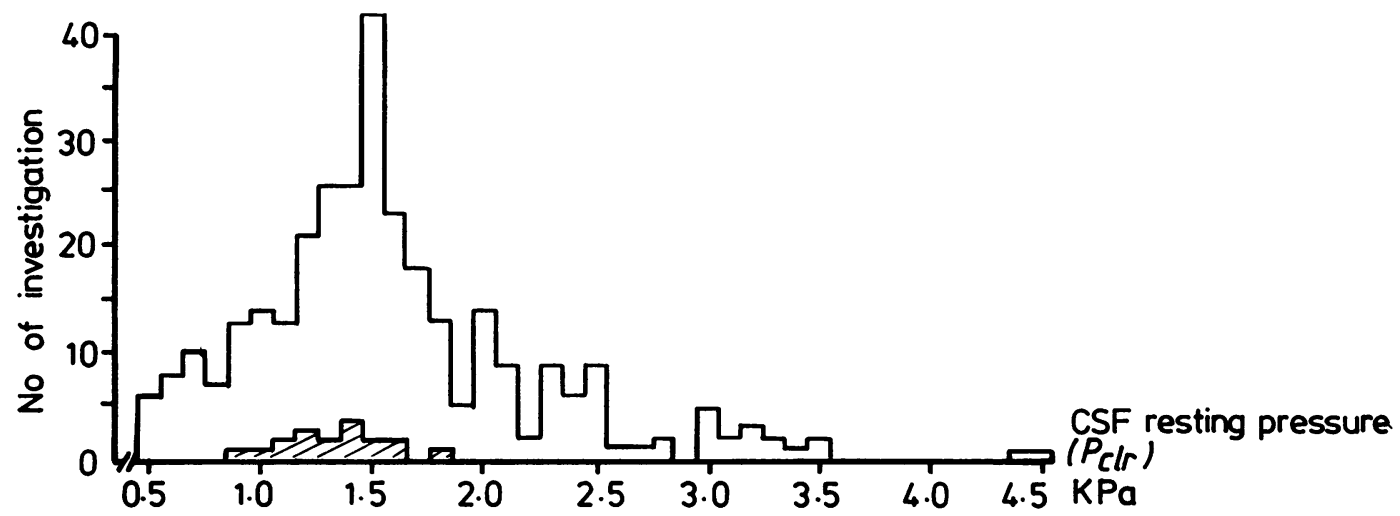

Fig 6 Distribution of the CSF resting pressure in 316 investigations. The shaded values correspond to 18 cases considered to be healthy on the basis of CSF and blood flow.

children had at some time an accelerated head growth and all had enlarged ventricles in neuroradiographic examinations or on echoencephalography. CSF infusion data in eight children with spontaneously arrested hydrocephalus are shown in table 4.

Non-communicating hydrocephalus. In one child with intraventricular obstruction, according to radiography performed later, a CSF resting pressure of $2.0 \mathrm{kPa}$ and pulse synchronous variation of $0.05 \mathrm{kPa}$ were recorded.

Macrocephalus. In nine children, four months to four years of age, a large head circumference was the main indication for examination. Many of the children had a positive heredity according to large heads. The psychomotor development was normal in seven of the children, slightly retarded in two. Echo-encephalography or pneumo-encephalography revealed normal sized ventricles. CSF resting-pressures between $0.9 \mathrm{kPa}$ and $11.5 \mathrm{kPa}$ were registered. CSF infusion data in four children with macrocephalus are given in table 5.

Subdural hematomas. Eight children with subdural 


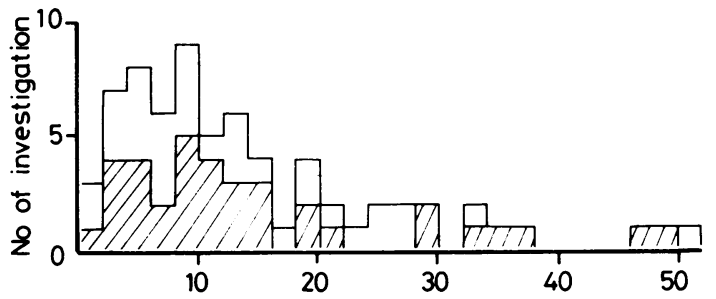

Hydrodynamic conductance of CSF outflow pathways $\left(G_{o p}\right)\left(\mathrm{mm}^{3} \mathrm{kPa}^{-1} \mathrm{~s}^{-1}\right)$

Fig 7 Distribution of the conductance of the CSF outflow pathways in 69 investigations. The shaded values correspond to 36 cases with a CSF resting pressure between 1.0 and $1.6 \mathrm{kPa}$ (5-95 per cent distribution). hematomas were investigated 1 to 3 months after obvious or suspected skull trauma. Data from CSF hydrodynamic studies in five of the children are given in table 6.

Craniosynostosis. Twelve patients with craniosynostosis were examined. The synostoses were either part of Apert's syndrome (two cases), Crouzon's disease (two cases) or isolated premature synostosis of sutura sagittalis (eight cases). In three cases the synostosis was the result of overfunction in a shunt system. There was papilloedema of 1-3 diopters in four cases. The results of the CSF hydrodynamic studies before, and in six cases also after, operation of the craniosynostosis are given in table 7.

Table 1 Age, CSF resting pressure, conductance and symptoms/diagnoses in 18 children considered as healthy on the basis of CSF and blood flow

\begin{tabular}{|c|c|c|c|c|}
\hline Case number & Age, months, years & $P_{c l r} k P a$ & $G_{o p} m m^{3} k P a^{-1} s^{-1}$ & Symptoms/diagnosis \\
\hline 2 & $1 \mathrm{~m}$ & $1 \cdot 1$ & - & muscular hypertonia \\
\hline 7 & $5 \mathrm{~m}$ & $1 \cdot 3$ & - & psychomotoric retardation \\
\hline 16 & $6 \mathrm{~m}$ & 0.9 & - & diadystrophic dwarf \\
\hline 21 & $8 \mathrm{~m}$ & $1 \cdot 5$ & - & accelerated skull growth \\
\hline 22 & $8 \mathrm{~m}$ & 1.4 & $5 \cdot 8$ & psychomotoric retardation \\
\hline 24 & $9 \mathrm{~m}$ & $1 \cdot 4$ & - & accelerated skull growth \\
\hline 28 & $10 \mathrm{~m}$ & $1 \cdot 2$ & $5 \cdot 8$ & microcephalus and microophtalmi \\
\hline 29 & $10 \mathrm{~m}$ & $1 \cdot 5$ & & macrocephalus \\
\hline 30 & $11 \mathrm{~m}$ & $1 \cdot 3$ & - & dysostosis cleido-cranialis \\
\hline 31 & $11 \mathrm{~m}$ & 1.6 & - & psychomotoric retardation \\
\hline 36 & $16 \mathrm{~m}$ & $1 \cdot 4$ & - & psychomotoric retardation \\
\hline 37 & $16 \mathrm{~m}$ & $1 \cdot 2$ & - & macrocephalus \\
\hline 38 & $17 \mathrm{~m}$ & 1.4 & - & nocturn episodic hypoventilation \\
\hline 54 & $4 y$ & $1 \cdot 8$ & - & psychmotoric retardation \\
\hline 56 & $5 y$ & $1 \cdot 1$ & $10 \cdot 2$ & "failure to thrive" \\
\hline
\end{tabular}

$5-95 \%$ within $1 \cdot 0-1 \cdot 6 \mathrm{kPa}$. Mean resting pressure $1 \cdot 3 \mathrm{kPa}$.

Table 2 CSF formation rate (at $0 \cdot 25-0.4 \mathrm{kPa}$ ) and other CSF hydrodynamic data in 18 children with different diagnoses two months to 15 years old

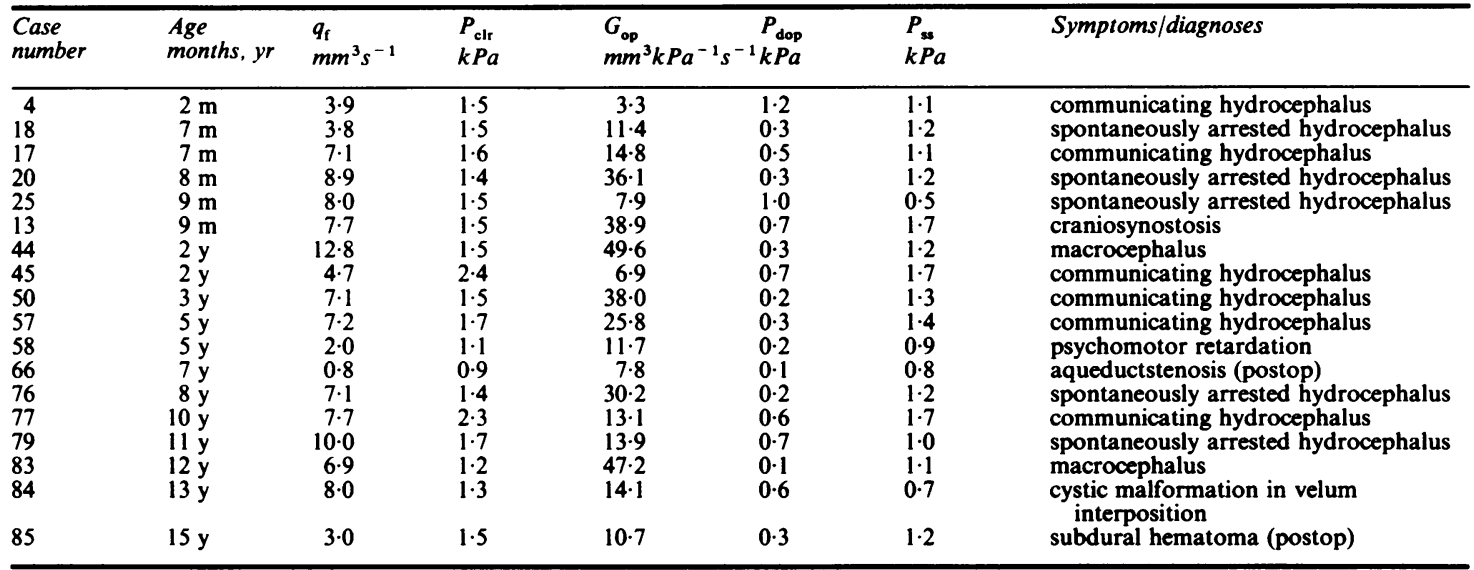

$5-95 \%$ of CSF formation rate within $3.0-10.0 \mathrm{~mm}^{3} \mathrm{~s}^{-1} ;$ mean $6.8 \mathrm{~mm}^{3} \mathrm{~s}^{-1}$

$5-95 \%$ of pressure difference across the CSF outflow pathways within $0.2-1.0 \mathrm{kPa}$, mean $0.5 \mathrm{kPa}$ (case $66 \mathrm{excluded}$ ). 
Table 3 CSF hydrodynamic data in six non-shunted children with communicating hydrocephalus

\begin{tabular}{|c|c|c|c|c|c|c|}
\hline $\begin{array}{l}\text { Case } \\
\text { number }\end{array}$ & $\begin{array}{l}\text { Age } \\
\text { months, yr }\end{array}$ & $\begin{array}{l}P_{\text {clr }} \\
k P a\end{array}$ & $\begin{array}{l}G_{\mathrm{op}} \\
m m^{3} k P a^{-1} s^{-1}\end{array}$ & $\begin{array}{l}q_{f} \\
m m^{3} s^{-1}\end{array}$ & $\begin{array}{l}P_{\text {dop }} \\
K P a\end{array}$ & $\begin{array}{l}P_{s s} \\
K P a\end{array}$ \\
\hline $\begin{array}{r}6 \\
12 \\
33 \\
45 \\
63 \\
77\end{array}$ & $\begin{array}{r}3 \mathrm{~m} \\
5 \mathrm{~m} \\
12 \mathrm{~m} \\
2 \mathrm{y} \\
6 \mathrm{y} \\
10 \mathrm{y}\end{array}$ & $\begin{array}{l}2 \cdot 1 \\
2 \cdot 1 \\
2 \cdot 0 \\
2 \cdot 4 \\
2 \cdot 5 \\
2 \cdot 3\end{array}$ & $\begin{array}{r}12.4 \\
2.9 \\
5.9 \\
6.9 \\
8.0 \\
13.1\end{array}$ & $\begin{array}{c}(6 \cdot 8) \\
(6 \cdot 8) \\
(6 \cdot 8) \\
4 \cdot 7 \\
(6 \cdot 8) \\
7 \cdot 7\end{array}$ & $\begin{array}{c}{[0.6]} \\
{[2.3]} \\
{[1.2]} \\
0.7 \\
{[0.9]} \\
0.6\end{array}$ & $\begin{array}{l}{[1 \cdot 6]} \\
{[-0.2]^{*}} \\
{[0.8]} \\
1 \cdot 7 \\
{[1 \cdot 6]} \\
1.7\end{array}$ \\
\hline
\end{tabular}

$($ ) = estimated value, [ ] = calculated from estimated value

* a negative $P_{s s}$ is not probable and due to the estimated value of $q_{f}$.

Table 4 CSF hydrodynamic data in eight children with "spontaneously arrested hydrocephalus"

\begin{tabular}{|c|c|c|c|c|c|c|}
\hline $\begin{array}{l}\text { Case } \\
\text { number }\end{array}$ & $\begin{array}{l}\text { Age } \\
\text { months, yr }\end{array}$ & $\begin{array}{l}P_{\text {clr }} \\
k P a\end{array}$ & $\begin{array}{l}G_{\text {op }} \\
m^{3} m^{3} \mathrm{~Pa}^{-1} s^{-1}\end{array}$ & $\begin{array}{l}q_{\mathrm{f}} \\
m m^{3} s^{-1}\end{array}$ & $\begin{array}{l}P_{\text {dop }} \\
K P a\end{array}$ & $\begin{array}{l}P_{\mathrm{ss}} \\
K P a\end{array}$ \\
\hline $\begin{array}{l}10 \\
17 \\
18 \\
18 \\
19 \\
20 \\
39 \\
42 \\
76\end{array}$ & $\begin{array}{r}4 \mathrm{~m} \\
7 \mathrm{~m} \\
7 \mathrm{~m} \\
14 \mathrm{~m} \\
7 \mathrm{~m} \\
8 \mathrm{~m} \\
17 \mathrm{~m} \\
18 \mathrm{~m} \\
8 \mathrm{y}\end{array}$ & $\begin{array}{l}1.0 \\
1.6 \\
1.5 \\
1.3 \\
1.0 \\
1.4 \\
1.4 \\
1.3 \\
1.4\end{array}$ & $\begin{array}{l}16.9 \\
14.8 \\
11.4 \\
11 \cdot 1 \\
36 \cdot 1 \\
33.4 \\
11.9 \\
30.2\end{array}$ & $\begin{array}{c}(6 \cdot 8) \\
7 \cdot 1 \\
3.8 \\
\\
(6 \cdot 8) \\
8.9 \\
(6.8) \\
(6.8) \\
7 \cdot 1\end{array}$ & $\begin{array}{c}{[0.4]} \\
0.5 \\
0.3 \\
\\
{[0.6]} \\
0.3 \\
{[0.2]} \\
{[0.6]} \\
0.2\end{array}$ & $\begin{array}{c}{[0.6]} \\
1.1 \\
1.2 \\
\\
{[0.4]} \\
1.2 \\
{[1 \cdot 2]} \\
{[0.7]} \\
1.2\end{array}$ \\
\hline
\end{tabular}

$($ ) = estimated value, $[$ ] = calculated from estimated value.

Table 5 Head size in standard deviation (SD) compared with the reference values for the Swedish population ${ }^{18}$ and CSF hydrodynamic data in four children with macrocephalus

\begin{tabular}{|c|c|c|c|c|c|c|c|}
\hline $\begin{array}{l}\text { Case } \\
\text { number }\end{array}$ & $\begin{array}{l}\text { Age } \\
\text { months, yr }\end{array}$ & $\begin{array}{l}\text { Head } \\
\text { size } S D\end{array}$ & $\begin{array}{l}P_{\text {clr }} \\
k P a\end{array}$ & $\begin{array}{l}G_{\mathrm{op}} \\
m m^{3} k \mathrm{~Pa}^{-1} s^{-1}\end{array}$ & $\begin{array}{l}q_{\mathrm{f}} \\
m m^{3} s^{-1}\end{array}$ & $\begin{array}{l}P_{\text {dop }} \\
K P a\end{array}$ & $\begin{array}{l}P_{\mathrm{ss}} \\
\mathrm{KPa}\end{array}$ \\
\hline $\begin{array}{r}9 \\
9 \\
14 \\
41 \\
44\end{array}$ & $\begin{array}{c}4 \mathrm{~m} \\
5 \mathrm{~m} \\
5 \mathrm{~m} \\
18 \mathrm{~m} \\
2 \mathrm{y}\end{array}$ & $\begin{array}{l}+3 \\
+3 \\
+2 \cdot 5 \\
+3 \\
+3\end{array}$ & $\begin{array}{l}1 \cdot 1 \\
1.4 \\
1 \cdot 1 \\
1 \cdot 0 \\
1 \cdot 5\end{array}$ & $\begin{array}{r}3.9 \\
10.8 \\
20.4 \\
49.6\end{array}$ & $\begin{array}{l}(6 \cdot 8) \\
(6 \cdot 8) \\
(6 \cdot 8) \\
12 \cdot 8\end{array}$ & $\begin{array}{c}{[1 \cdot 7]} \\
{[0.6]} \\
{[0.3]} \\
0.3\end{array}$ & $\begin{array}{l}{[-0.3]^{*}} \\
{[0 \cdot 5]} \\
{[0 \cdot 7]} \\
1 \cdot 2\end{array}$ \\
\hline
\end{tabular}

) = estimated value, [ ] = calculated from estimated value

*a negative $P_{s s}$ is not probable and due to the estimated value of $q_{f}$.

Table 6 CSF hydrodynamic data in five children with subdural effusions

\begin{tabular}{|c|c|c|c|c|c|c|}
\hline $\begin{array}{l}\text { Case } \\
\text { number }\end{array}$ & $\begin{array}{l}\text { Age } \\
\text { months, yr }\end{array}$ & $\begin{array}{l}P_{\text {clr }} \\
k P a\end{array}$ & $\begin{array}{l}G_{\mathrm{op}} \\
m m^{3} k \mathrm{~Pa}^{-1} s^{-1}\end{array}$ & $\begin{array}{l}q_{\mathrm{f}} \\
\mathrm{mm}^{3} \mathrm{~s}^{-1}\end{array}$ & $\begin{array}{l}P_{\text {dop }} \\
K P a\end{array}$ & $\begin{array}{l}P_{\mathrm{sa}} \\
\mathrm{KPa}\end{array}$ \\
\hline $\begin{array}{l}26 \\
32 \\
61 \text { (postop) } \\
61 \\
78 \\
85\end{array}$ & $\begin{array}{r}9 \mathrm{~m} \\
11 \mathrm{~m} \\
6 \mathrm{y} \\
8 \mathrm{y} \\
10 \mathrm{y} \\
15 \mathrm{y}\end{array}$ & $\begin{array}{l}1.2 \\
0.7 \\
0.6 \\
0.6 \\
1.5 \\
1.5\end{array}$ & $\begin{array}{r}19 \cdot 4 \\
6.0 \\
32.9 \\
\\
29 \cdot 5 \\
10.7\end{array}$ & $\begin{array}{c}(6 \cdot 8) \\
(6 \cdot 8) \\
(6 \cdot 8) \\
(6.8) \\
3.0\end{array}$ & $\begin{array}{c}{[0.4]} \\
{[1.0]} \\
{[0.2]} \\
{[0.2]} \\
0.3\end{array}$ & $\begin{array}{l}{[0 \cdot 8]} \\
{[-0.3]^{*}} \\
{[0 \cdot 4]} \\
{[1 \cdot 3]} \\
1 \cdot 2\end{array}$ \\
\hline
\end{tabular}

) = estimated value, $[$ ] = calculated from estimated value

*a negative $P_{s s}$ is not probable and due to the estimated value of $q_{f}$.

Complications to the CSF hydrodynamic investigation In three children symptoms of intracranial hypertension appeared after the examination. All three children had malfunctioning shunt systems. One girl operated for myelomeningocele after the termination of a CSF hydrodynamic investigation showed leakage of CSF in the back through the puncture canals of the needles.

Four children acquired symptoms indicating meningitis. In one of them staph. albus was isolated from the CSF. In the three other cases no bacteria were shown and the equipment and the fluids used were in 
Table 7 CSF hydrodynamic data and presence of papilloedema in 12 children with craniosynostosis

\begin{tabular}{|c|c|c|c|c|c|c|c|c|}
\hline $\begin{array}{l}\text { Case } \\
\text { number }\end{array}$ & Diagnosis (operation) & $\begin{array}{l}\text { Age, } \\
\text { months, yr }\end{array}$ & Papilloedema & $\begin{array}{l}P_{\text {clr }} \\
k P a\end{array}$ & $\begin{array}{l}G_{\mathrm{op}} \\
m m^{3} \mathrm{kPa}^{-1} s^{-1}\end{array}$ & $\begin{array}{l}q_{f} \\
m m^{3} s^{-1}\end{array}$ & $\begin{array}{l}P_{\text {dop }} \\
k P a\end{array}$ & $\begin{array}{l}P_{\mathrm{ss}} \\
k P a\end{array}$ \\
\hline $\begin{array}{r}52 \\
8 \\
8 \\
13 \\
13 \\
13 \\
46 \\
47 \\
87 \\
68 \\
65 \\
65 \\
65\end{array}$ & 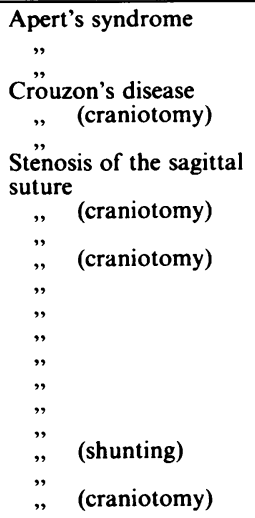 & $\begin{array}{l}2 \mathrm{~m} \\
3 \mathrm{~m} \\
18 \mathrm{~m} \\
2 \mathrm{y} 7 \mathrm{~m} \\
3 \mathrm{y} \\
7 \mathrm{y} \\
3 \mathrm{y} 7 \mathrm{~m} \\
4 \mathrm{y} \\
3 \mathrm{~m} \\
6 \mathrm{~m} \\
5 \mathrm{~m} \\
9 \mathrm{~m} \\
11 \mathrm{~m} \\
2 \mathrm{y} \\
2 \mathrm{y} \\
5 \mathrm{y} \\
7 \mathrm{y} \\
4 \mathrm{y} \\
6 \mathrm{y} \\
7 \mathrm{y}\end{array}$ & $\begin{array}{l}+ \\
- \\
+ \\
- \\
- \\
- \\
- \\
+ \\
- \\
- \\
- \\
- \\
- \\
-\end{array}$ & $\begin{array}{l}3.2 \\
1.5 \\
1.5 \\
1.3 \\
1.2 \\
1.2 \\
1.5 \\
2.0 \\
1.7 \\
1.5 \\
1.6 \\
0.8 \\
2.5 \\
1.4\end{array}$ & $\begin{array}{r}4.3 \\
23.5 \\
8.8\end{array}$ & $\begin{array}{l}(6 \cdot 8) \\
(6 \cdot 8)\end{array}$ & $\begin{array}{l}{[0 \cdot 3]} \\
{[0 \cdot 8]}\end{array}$ & $\begin{array}{l}{[-0 \cdot 3]^{*}} \\
{[2 \cdot 9]}\end{array}$ \\
\hline
\end{tabular}

$($ ) = estimated value, $[$ ] = calculated from estimated value

*a negative $P_{s s}$ is not possible and due to the estimated value of $q_{f}$.

all cases sterile; in two of the cases, however, the infusion fluid proved to contain pyrogens. All patients recovered fully.

\section{Discussion}

\section{THE CONSTANT PRESSURE INFUSION METHOD} IN CHILDHOOD

Increased intracranial pressure is a serious condition. It may cause mental and/or neurological deterioration and also death. An early and unequivocal diagnosis of increased intracranial pressure is important both in the neonatal period and later on. Complications of shunt treatment are common and sometimes difficult to recognise. The CSF hydrodynamic examination must, together with other methods, be evaluated in this context.

Some authors have tried to obtain information on the CSF hydrodynamics by non-invasive methods. Thus Edward ${ }^{19}$ used a modified Schiotz tonometer, Blaauw et al. ${ }^{20}$ used a stethoscope connected to a pulse-pickup and Wealthall and Smallwood ${ }^{21}$ used an applanation tonometer to the intact fontanelle in an attempt to record the intracranial pressure. The latter method has been used by others ${ }^{22-26}$ but it is restricted to small children and gives information only related to the CSF pressure; no information is obtained on other CSF hydrodynamic parameters.

Several invasive methods have been used to identify raised intracranial pressure. Minns ${ }^{27}$ lists the following: open ended manometric method of CSF displacement, Hopperstein's balloon in the subdural or subarachnoid space, pressure-indicating bag, transducer device situated within brain tissue, implantable minia- ture pressure transducer for epidural measurement, completely inplantable telemetry transducer and catheters into ventricle or needling of Pudenz or Rickham system and connection to a strain gauge transducer. Most of these methods are complicated and require neurosurgical intervention.

We used the constant pressure infusion method in children of different ages. The examination was employed without general anaesthesia but necessitated time and patience from both the child and the staff. The dimensions of the needles must not be too small. The position of the needles must be correct and stable throughout the whole investigation. Owing to physical (such as kyphoscoliosis), psychological or technical reasons this was not always achieved. In the youngest children with open sutures the skull was very compliant. Any elevation of the intra-cranial pressure in these cases directly resulted in an increased skull volume.

\section{THE NORMAL CSF HYDRODYNAMIC VALUES IN CHILDREN}

\section{The CSF resting pressure}

The CSF resting pressure in our "healthy" children aged 1 month to 15 years had a $5-95 \%$ range of $1.0-1.6 \mathrm{kPa}$ with a mean of $1.3 \mathrm{kPa}$.

There are relatively few reports of the CSF resting pressure in normal children. Quincke ${ }^{28}$ in 1902 gave a value in $\mathrm{mm} \mathrm{Hg}$ comparable to $0.5 \mathrm{kPa}$. Sidbury ${ }^{29}$ gave figures comparable to $0.3-0.7 \mathrm{kPa}$, Levinson ${ }^{30}$ $0.1-0.8 \mathrm{kPa}$, Munro $^{31} 0.3-0.8 \mathrm{kPa}$, Lups and Haan ${ }^{32}$ 0.4-1.0 kPa, Brock and Dietz ${ }^{33}$ less than $1.3 \mathrm{kPa}$, Minns and Brown ${ }^{34}$ less than $1.6 \mathrm{kPa}$, Di Rocco et al ${ }^{9}$ 
Table 8 CSF hydrodynamic 5-95\% range and mean values in 15 children with "normal" CSF resting values and in 58 normal adults $^{12}$

\begin{tabular}{|c|c|c|c|c|c|}
\hline & $\begin{array}{l}P_{\text {clr }} \\
k P a\end{array}$ & 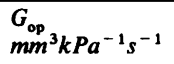 & $\begin{array}{l}q_{f} \\
m m^{3} s^{-1}\end{array}$ & $\begin{array}{l}P_{\text {dop }} \\
k P a\end{array}$ & $\begin{array}{l}P_{\mathrm{ss}} \\
k P a\end{array}$ \\
\hline $\begin{array}{l}\text { Children } \\
5-95 \%\end{array}$ & & & & & \\
\hline $\begin{array}{l}\text { range } \\
\text { mean } \\
\text { Adults } \\
5-95 \%\end{array}$ & $\begin{array}{l}1 \cdot 0-1 \cdot 6 \\
1 \cdot 3\end{array}$ & $\begin{array}{l}6 \cdot 9-47 \cdot 2 \\
22 \cdot 6\end{array}$ & $\begin{array}{l}3 \cdot 0-10 \cdot 0 \\
6 \cdot 8\end{array}$ & $\begin{array}{l}0.1-1.0 \\
0.5\end{array}$ & $\begin{array}{l}0 \cdot 7-1 \cdot 7 \\
1 \cdot 1\end{array}$ \\
\hline $\begin{array}{l}\text { range } \\
\text { mean }\end{array}$ & $\begin{array}{l}1 \cdot 2-1 \cdot 8 \\
1 \cdot 4\end{array}$ & $\begin{array}{l}12 \cdot 0-26 \cdot 0 \\
18 \cdot 0\end{array}$ & $\begin{array}{l}4.5-9.5 \\
6.7\end{array}$ & $\begin{array}{l}0.3-0.6 \\
0.4\end{array}$ & $\begin{array}{l}0.7-1.4 \\
1.0\end{array}$ \\
\hline
\end{tabular}

less than $1.9 \mathrm{kPa}$, Foltz ${ }^{35}$ less than $1.4 \mathrm{kPa}$ and Portnoy and Croissant ${ }^{36}$ and Bell and McCormick ${ }^{37}$ less than $1.8 \mathrm{kPa}$. The methods used and the number and age of the investigated children are not always specified but the given values have been used as references.

Several authors have recorded the anterior fontanelle pressure in normal newborn children with the aid of non-invasive techniques. Thus Welch ${ }^{38}$ by tilting the child and recording the position in which the fontanelle flattened estimated the normal intracranial pressure in ten children to $0.4 \pm 0.2 \mathrm{kPa}$. Salmon et al $^{25}$ by using an applanation transducer determined the normal intracranial pressure in newborn infants to $1.0 \pm 0.2 \mathrm{kPa}$, Robinson et $^{2 l^{24}}$ used the similar technique and reported values of $1.5 \pm 0.4 \mathrm{kPa}$ and Vidyasager et $^{23}$ found values of $1.4 \pm 0.1 \mathrm{kPa}$. Donn and Philips ${ }^{26}$ in 18 preterm infants recorded a significant increase of the anterior fontanelle pressure from birth to age 24 hours and a significant decrease by 48 hours of age $1.4 \mathrm{vs} 2.4$ and $1.4 \mathrm{kPa}$ ).

The pressure recorded through the anterior fontanelle is influenced by the elasticity of meninges, subcutaneous and cutaneous tissue. However, both Vidyasager and Raju, ${ }^{22}$ and Donn and Philip ${ }^{26}$ claim good correlation between the pressure obtained over the anterior fontanelle and the CSF pressure measured during ventricular tap and lumbar punctures.

In most earlier studies the CSF pressure was recorded immediately after insertion of the needle. In that situation the child may be anxious and the CSF pressure elevated. If, on the other hand, the child is squealing or hyperventilating the CSF pressure may be decreased. The earlier use of open manometry and subsequent loss of liquor may be another factor influencing the results.

Our investigations have been done in strictly isometric conditions at the end of a recording period of 30-60 minutes with the child relaxed in the supine position. The $5-95 \%$ range $(1.0-1.6 \mathrm{kPa})$ and the mean $(1.3 \mathrm{kPa})$ of the CSF resting pressure in our children are compatible with the values for normal adults $(1.2-1.8$ and $1.4 \mathrm{kPa})$, respectively, given by Ekstedt; (table 8).
The normal CSF pressure conditions, especially in newborn infants, need further investigation. The whole concept of "normal" CSF pressure is under discussion. Adams et $\mathrm{l}^{39}$ pointed out that the force on the wall of a fluid-filled container is equal to the product of pressure and surface area over which the pressure is exerted. Thus, in addition to the CSF pressure recorded, the size of the ventricles is of importance when considering any damaging effect on the surrounding brain. The exact size of the ventricular system, has, however, not been determined in the children in the present study.

The conductance of the CSF outflow pathways

Information on the conductance of CSF outflow pathways in normal children is not available in the literature. The conductance in three "healthy" children in the present study was 5.8, 5.8 and 10.2 $\mathrm{mm}^{3} \mathrm{kPa}^{-1} \mathrm{~s}^{-1}$ (table 1). In cases with different diagnosis but with CSF resting pressure within the "normal" range $1.0-1.6 \mathrm{kPa}$ the conductance ranged $2 \cdot 0-38.9 \mathrm{~mm}^{3} \mathrm{kPa}^{-1} \mathrm{~s}^{-1}$ (fig 7).

Cutler $\mathrm{et} \mathrm{al}^{4}$ using the ventriculo-lumbar perfusion technique in examining eight children with subacute sclerosing panencephalitis and four children with pontine gliomas found a conductance of about 13 $\mathrm{mm}^{3} \mathrm{kPa}^{-1} \mathrm{~s}^{-1}$ and Martins ${ }^{40}$ using the constant infusion technique in seven patients (age and diagnosis not given) found a conductance of 8-24 $\mathrm{mm}^{3} \mathrm{kPa}^{-1} \mathrm{~s}^{-1}$ Portnoy and Croissant ${ }^{15}$ in nine children with myelomeningocele and hydrocephalus investigated with a constant CSF pressure method before shunting found a conductance of $6 \cdot 3-38.6$ $\mathrm{mm}^{3} \mathrm{kPa}^{-1} \mathrm{~s}^{-1}$. Caldarelli et al ${ }^{10}$ used the subarachnoidal infusion test in three groups of children. In one group of 28 non-shunted hydrocephalic children they found a conductance of 2.8-11.6 $\mathrm{mm}^{3} \mathrm{kPa}^{-1} \mathrm{~s}^{-1}$. In another group of 21 children with a diagnosis of cerebral atrophy the value of the conductances fluctuated from 6.7 to $21 \cdot 1 \mathrm{~mm}^{3} \mathrm{kPa}^{-1} \mathrm{~s}^{-1}$ and in a third group of 10 children with craniosynostosis or microcephalia conductance values between 4.0 and $12.7 \mathrm{~mm}^{3} \mathrm{kPa}^{-1} \mathrm{~s}^{-1}$ were obtained.

In all these cited investigations the values for con- 
ductance or resistance have been given in other unit values but are by us recalculated as conductance in SI values. Ekstedt ${ }^{14}$ gave the following values for conductance in normal adults: $12-26 \mathrm{~mm}^{3} \mathrm{kPa}^{-1} \mathrm{~s}^{-1}$.

Our figures seem to be in quite good agreement with the results of the cited authors. The wide range of the values probably depends on the compliant skull in young children.

\section{CSF formation rate}

The 5-95\% range of the CSF formation rate found in the present study in 17 children with different diagnoses (table 2) was $3.0-10.0 \mathrm{~mm}^{3} \mathrm{~s}^{-1}$ with a mean of $6.8 \mathrm{~mm}^{3} \mathrm{~s}^{-1}$.

The CSF formation rate in quite healthy children is not given in the literature. Using perfusion techniques in 12 hydrocephalic children Lorenzo et $\mathrm{al}^{5}$ found a CSF formation rate mean value of $5.0 \mathrm{~mm}^{3} \mathrm{~s}^{-1}$ and in eight hydrocephalic children Page $e a^{41}$ found a mean value of $4.6 \mathrm{~mm}^{3} \mathrm{~s}^{-1}$. Portnoy and Croissant ${ }^{15}$ using a constant pressure drainage method in nine children with myelomeningocele and hydrocephalus found a mean CSF formation rate of $4.8 \mathrm{~mm}^{3} \mathrm{~s}^{-1}$.

An elevated CSF pressure may reduce the CSF formation rate but in one of our cases with a CSF resting pressure of $2.4 \mathrm{kPa}$ the CSF formation rate at $0.25 \mathrm{kPa}$ was $7.7 \mathrm{~mm}^{3} \mathrm{~s}^{-1}$ (table 2).

Conclusions regarding any relation between the CSF formation rate and the age and diagnoses cannot be drawn from this limited material. In normal adults Ekstedt ${ }^{14}$ found a $5-95 \%$ range of $4 \cdot 5-9.5 \mathrm{~mm}^{3} \mathrm{~s}^{-1}$ with a mean of $6.7 \mathrm{~mm}^{3} \mathrm{~s}^{-1} \pm 1.4$ (SD). The mean value for children in the present investigation is very similar.

\section{The pressure difference across the CSF outflow pathways}

The normal value of the pressure difference across the CSF outflow pathways in children has not so far been known. The mean values in 17 of our children (with known CSF formation rate, table 2) was $0.5 \mathrm{kPa}$ with a $5-95 \%$ range of $0 \cdot 2-1 \cdot 0 \mathrm{kPa}$. Ekstedt ${ }^{14}$ in normal adults obtained the comparable values 0.4 and $0.3-0.6 \mathrm{kPa}$, respectively.

\section{The pressure in sinus sagittalis}

A simple, safe method for directly registering the pressure in sagittal sinus is desirable but so far not available. The pressure in sagittal sinus can be calculated from the recorded values of resting pressure, conductance and CSF formation rate (see above). Any inaccuracy in these will be reflected in the value of the pressure of sinus sagittalis. When a fixed estimated value of the CSF formation rate of $6.8 \mathrm{~mm}^{3} \mathrm{~s}^{-1}$ is used, the calculated pressure in sagittal sinus will sometimes be negative. A negative sagittal sinus pres- sure is not probable. The CSF formation rate has in such a case been incorrectly estimated. With another value of the CSF formation rate the calculated pressure in sagittal sinus becomes positive. The number of investigations including CSF formation rate recording and thus including a "true" value of the pressure in sinus sagittalis is too small for a conclusion to be drawn. The distribution and mean $(0.4-1 \cdot 7 \mathrm{kPa}, 1 \cdot 1$ $\mathrm{kPa})$ are, however, in agreement with comparable values $(0.7-1.4 \mathrm{kPa}$ and $1.0 \mathrm{kPa})$ in normal adults. ${ }^{14}$

\section{The CSF hydrodynamic variables in children}

The $5-95 \%$ range and the mean values of the hydrodynamic variables for some children are summarized in table 8. It must again be underlined that the "healthy" status concerning the CSF hydrodynamic in our children (table 1) is probable but not proven. As there are no comparable figures for healthy children and figures for normal adults ${ }^{14}$ are also given. When making a comparison one must remember the differences in the subjects studied. However, there seems, in general, to be good agreement between the different CSF hydrodynamic values in those children and normal adults. The figures may be used as provisional reference values in clinical work.

\section{THE USE OF THE CONSTANT PRESSURE}

INFUSION METHOD IN NEUROPAEDIATRICS

A suspicion of increased intracranial pressure can be confirmed or sustained by a CSF resting pressure recording. Sometimes, of course, borderline results are obtained. A complete CSF hydrodynamic investigation gives information also of the conductance and the formation rate of the cerebrospinal fluid and indirectly of the pressure over the CSF outflow pathways and in the sagittal sinus.

A mixed group of children, like the one investigated by us, must be heterogeneous from the CSF hydrodynamic point of view. The relatively small number of patients in the different groups of diagnosis do not permit statistical analysis. Certain conclusions can, however, be drawn. The age for closing of fontanelles and sutures varies. ${ }^{42}$ The age at closing is probably more important than the chronological age when considering the CSF hydrodynamics. In children with open fontanelles and sutures the highest recorded CSF resting pressure was $2.8 \mathrm{kPa}$ while in cases with closed fontanelles, CSF resting pressure up to $4.3 \mathrm{kPa}$ as well as plateau waves at $12 \mathrm{kPa}$ were recorded. Owing to the damping effect of compliant skull and pulse and respiration synchronous pressure variations were smaller in children with open fontanelles and sutures than in those with closed ones.

\section{Communicating hydrocephalus}

Our children with a non-shunted communicating 
hydrocephalus (table 3) had elevated CSF resting pressures and rather low conductances and either a somewhat elevated pressure difference across the CSF outflow pathways (cases 12 and 33) or elevated pressure in the sagittal sinus (cases 6, 45 and 77) or a combination (case 63) with some elevation of both these pressures. This is in accordance with what has been found by Portnoy and Croissant ${ }^{16}$ using essentially the same method. A hydrocephalus must not always be caused by a defect in the cerebrospinal fluid system but may be caused by an elevated pressure in sagittal sinus which in turn may be caused by thromboses in the veins. It seems reasonable that those who would respond favourably to compressive head wrapping ${ }^{43}$ would be those with elevated pressure in sagittal sinus.

\section{Spontaneously arrested hydrocephalus}

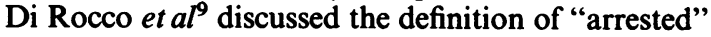
hydrocephalus and stated that when the size of the intracranial spaces containing CSF stops an abnormal progressive dilatation and follows the normal rate increase related to growth, the hydrocephalus might be regarded as "arrested".

Hagberg and $\mathrm{Naglo}^{44}$ in a study of 45 conservatively managed hydrocephalic children concluded that conservative management was justifiable during the first 5-6 months of life in slowly progressive cases but no longer if the increase in skull growth then seemed uncompensated. They found no safe criteria for aiding in the decision regarding operation. Bird et $a l^{8}$ studied four patients with suspected arrested communicating hydrocephalus with constant infusion saline manometry. In three cases the diagnosis was confirmed. However, in one child the headgrowth, clinical signs and skull radiographs were misleading. The infusion pattern was abnormal and the child needed a shunt. Di Rocco et $a l^{9}$ investigated 18 children having hydrocephalus which could be regarded clinically as "arrested". With the constant flow infusion manometric test they revealed normal CSF resting pressures but still "active" hydrocephalus in seven children. Caldarelli et al ${ }^{10}$ employing the lumbar subarachnoid infusion test recorded CSF pressures above normal limits in three of five children clinically regarded to have "arrested" hydrocephalus.

In the present study children with elevated CSF resting pressure were not classified as arrested. In arrested cases examined hydrodynamically (table 4) none had an increased pressure in the sagittal sinus or over the CSF outflow pathways but the conductance values seemed to be higher in this group than in cases with uncompensated hydrocephalus (table 3 ).

Non-communicating hydrocephalus

In infants with very fast headgrowth a non- communicating hydrocephalus must be suspected. The viscoelasticity of the content of the skull and the spine usually results in a good correlation between the intraventricular and lumbar pressures but in noncommunicating hydrocephalus they may not be equal and a hydrodynamic study with a lumbar approach may thus be of limited value. Furthermore, a lumbar CSF removal may give rise to a tentorial herniation. ${ }^{4546}$ The risk of this is however slight as long as fontanelles and sutures are unclosed.

In one examined case with aqueduct stenosis (case 66, table 2) the CSF resting pressure was normalised after a shunting procedure. The low value of the CSF formation rate $\left(0.8 \mathrm{~mm}^{3} \mathrm{~s}^{-1}\right)$ does not represent the true situation in the skull cavity.

\section{Macrocephalus}

Children with occipito-frontal head circumference exceeding 2 SD of the mean for their chronological age are often designated macrocephalic. Macrocephaly can be the result of different intra- or extracerebral processes but is usually a familial characteristic in quite normal individuals. ${ }^{47}$ Ellison ${ }^{48}$ reviewed 44 children with inappropriately enlarging heads. She considered computed tomography (CT) a safe noninvasive technique for measurement of ventricular size and stated that infants with inappropriately enlarging heads after the neonatal or early infant period need careful evaluation and follow up but the majority will not be candidates for a shunt. Day and Schutt ${ }^{49}$ studied 15 normal children with large heads (circumference more than $0.5 \mathrm{~cm}$ above the 98 th centile in the graphs of Nellhaus) and found ventricular measurements of CT scan within normal range in all but one. Eleven of the children had one parent with a large head and as in the family described by Asch and Myers $^{47}$ there was a predominance of males.

Portnoy and Croissant ${ }^{16}$ examined seven boys with the diagnosis megaloencephaly according to the criteria of DeMyer. ${ }^{50}$ In radiographic examinations they found the ventricular size normal or minimally enlarged and non-progressive and in CSF hydrodynamics studied through a modified constant pressure infusion method they found a normal conductance and calculated an elevated sagittal sinus pressure. They postulated that a megaloencephaly is developed from an increase in parenchymal fluid volume secondary to an increase in sagittal sinus pressure. The minimal nonprogressive hydrocephalus seen in some of these infants may be explained by coexistence of the increase in sagittal sinus pressure with open cranial sutures resulting in a transient nonhydrostatic loading of the brain parenchyma.

Our hydrodynamically examined macrocephalic children had relatively moderate head sizes (table 5). None of them had, at the time of the investigation, an 
elevated pressure in the sagittal sinus but one case had a very high conductance. The significance of this is unclear.

\section{Subdural hematomas}

The size, number and position of subdural effusions should have importance for CSF dynamics as subdural fluid collections may interfere with the absorption of CSF. A low conductance noticed in case 32 (table 6) points to such a mechanism; case 78 , however, had a higher conductance than normal. The high conductance and the low CSF resting pressure recorded in case 61 was probably caused by the shunt.

\section{Craniosynostosis}

Moss in his review ${ }^{51}$ of the functional anatomy of cranial synostosis underlines that the sutures are the locus of secondary compensatory and mechanically obligatory growth which follows a prior separation of adjacent cranial bones. When compensatory possibilities in the skull are lacking severe symptoms such as increased intracranial pressure, papilloedema, optic nerve atrophy and mental retardation may arise. $^{52}$

In our cases (table 7) the craniosynostosis was either the result of a primary defect or of a shunting procedure. The variability in symptoms was great. Most cases with an elevated CSF resting pressure had papilloedema but not all of them. Case 65 illustrates the situation after a shunting procedure; a low CSF resting pressure and craniosynostosis was followed by an elevated intracranial pressure. The pressure was normalised by the subsequent craniotomy.

\section{Complications of the investigation}

No signs of tentorial herniation occurred. However, in three cases shunt dysfunction was proved and the children acquired symptoms of intracranial hypertension while waiting for shunt revision. One child with an elevated CSF resting pressure showed leakage of CSF through the puncture canals after the investigation. To avoid this, later on, the skin was pushed somewhat aside before the punctures especially in cases of myelomeningocele. Although strict antiseptic conditions were maintained four of the children developed meningitis. The demonstrated Staphylococcus albus in one case may be pathogenic but this was not proven. All the children recovered quickly. To avoid pyrogens the control of the artificial CSF was improved. Some children suffered minor complications such as transient thigh pain, low back pain or postural headache but in most cases there were no symptoms at all. With due precautions the complications of the investigation are few but the children should be closely observed during and after the investigation and CSF hydrodynamic studies should be restricted to hospitals with a neurosurgery department.

This work was supported by grants from the Swedish Medical Research Council (B 74-04X-4125), the Margareta Home Foundation and the Folke Bernadotte Foundation.

\section{References}

${ }^{1}$ Welch K. The principles of physiology of the cerebrospinal fluid in relation to hydrocephalus including normal pressure hydrocephalus. In: Frielander W, ed. Advances in Neurology. New York: Raven Press, 1975;13: 247-332.

${ }^{2}$ Hakim S, Venegas JG, Burton JD. The physics of the cranial cavity hydrocephalus and normal pressure hydrocephalus: Mechanical interpretation and mathematical model. Surg Neurol 1976;5:187-210.

${ }^{3}$ Rubin RC, Henderson ES, Ommaya AK, Walker MD, Rall DP. The production of cerebrospinal fluid in man and its modification by acetazolamide. $J$ Neurosurg 1966;25:430-6.

${ }^{4}$ Cutler RWP, Page LK, Galichich J, Watters GV. Formation and absorption of cerebrospinal fluid in man. Brain 1968;91:707-20.

${ }^{5}$ Lorenzo AV, Page KL, Watters GV. Relationship between cerebrospinal fluid formation, absorption and pressure in human hydrocephalus. Brain 1970;93:679-92.

${ }^{6}$ Katzman R, Hussey F. A simple constant-infusion manometric test for measurement of CSF absorption. I. Rationale and method. Neurology (Minneap) 1970; 20:534-44.

${ }^{7}$ Masserman JH. Cerebrospinal hydrodynamics. Clinical experimental studied. Arch Neurol Psychiatr 1934; 32:523-53.

${ }^{8}$ Bird MT, Ratcheson RA, Siegel BA, Fishman MA. The evaluation of arrested communicating hydrocephalus utilizing cerebrospinal fluid dynamics: a preliminary report. Dev Med Child Neurol 1973;15:474-82.

${ }^{9}$ Di Rocco C, Caldarelli M, Maira G, Rossi GF. The study of cerebrospinal fluid dynamics in apparently "arrested" hydrocephalus in children. Childs Brain 1977;3:359-74.

${ }^{10}$ Caldarelli M, Di Rocco C, Rossi GF. Lumbar subarachnoid infusion test in paediatric neurosurgery. $\mathrm{Dev}$ Med Child Neurol 1979;21:71-82.

${ }^{11}$ Ekstedt J. CSF hydrodynamics studied by means of constant pressure infusion technique. In: Lundberg N, Pontén U, Brock M, eds. Intracranial Pressure II. Berlin: Springer, 1975:35-41.

${ }^{12}$ Ekstedt J. CSF hydrodynamic studies in man. 1. Method of constant pressure CSF infusion. J Neurol Neurosurg Psychiatry 1977;49:105-19.

${ }^{13}$ Ekstedt J, Fridén H. CSF hydrodynamic especially in the adult hydrocephalus syndrome. In: Beks JWF, Bosch DA, Brock M. Intracranial Pressure III. Berlin: Springer, 1976:177-85.

${ }^{14}$ Ekstedt J. CSF hydrodynamic studies in man. 2. Normal hydrodynamic variables related to CSF pressure and flow. J Neurol Neurosurg Psychiatry 1978;41:345-53. 
${ }^{15}$ Portnoy HD, Croissant PD. Pre- and postoperative cerebrospinal fluid absorption studies in patients with myelomeningocele shunted for hydrocephalus. Childs Brain 1978;4:47-64.

${ }^{16}$ Portnoy HD, Croissant PD. Megaloencephaly in infants and children. The possible role of increased dural sinus pressure. Arch Neurol 1978;35:306-16.

${ }^{17}$ Davson H, Hollingworth G, Segae MB. The mechanism of drainage of the cerebrospinal fluid in man. Brain 1970;93:665-78.

${ }^{18}$ Karlberg P, Klackenberg G, Engström J. The development of children in a Swedish urban community. A prospective longitudinal study. Acta Paediatr Scand 1968;Suppl 187:

${ }^{19}$ Edwards J. An intracranial pressure-tonometer for use on neonates: preliminary report. Dev Med Child Neurol 1974;16 (Suppl 32):38-9.

${ }^{20}$ Blaauw G, van der Bos JL, Mus A. On pulsations of the fontanelle. Dev Med Child Neurol 1974;16 (Suppl 32):23-6.

${ }^{21}$ Wealthall SR, Smallwood R. Methods of measuring intracranial pressure via the fontanelle without puncture. J Neurol Neurosurg Psychiatry 1974;37:88-96.

${ }^{22}$ Vidyasager D, Raju TNK. A simple noninvasive technique of measuring intracranial pressure in the newborn. Pediatrics 1977;59 (Suppl):957.

${ }^{23}$ Vidyasager D, Raju TNK, Chian J. Clinical significance of monitoring anterior fontanel pressure in sick neonates and infants. Pediatrics 1978;62:996-9.

${ }^{24}$ Robinson RO, Rolfe P, Sutton P. Non-invasive method for measuring intracranial pressure in normal newborn infants. Dev Med Child Neurol 1977;19:305-8.

${ }^{25}$ Salmon JH, Hajjar W, Bada HS. The Fontogram: a noninvasive intracranial pressure monitor. Pediatrics 1977;60:721-5.

${ }^{26}$ Donn SM, Philip AGS. Early increase in intracranial pressure in preterm infants. Pediatrics 1978;61:904-7.

${ }^{27}$ Minns RA. Clinical application of ventricular pressure monitoring in children. $Z$ Kinderchir 1977;22:430-43.

${ }^{28}$ Quincke H. Ueber Lumbalpunktion. Die Deutsche Klinik 1902;6:351-88.

${ }^{29}$ Sidbury JB. The importance of lumbar puncture in intracranial hemorrhage of the new-born. Report of a case with recovery. Arch Pediatr 1920;37:545-53.

${ }^{30}$ Levinson A. Cerebrospinal fluid in infants and in children. Am J Dis Child 1928;36:799-818.

${ }^{31}$ Munro D. Cerebrospinal fluid pressure in the new-born. JAMA 1928;90:1688-9.

${ }^{32}$ Lups S, Haan A. The Cerebrospinal Fluid. Amsterdam: Elsevier 1954.

${ }^{33}$ Brock M, Dietz H. Intracranial Pressure. Experimental and Clinical Aspects. Berlin: Springer Verlag, 1972.

${ }^{34}$ Minns RA, Brown JK. Intracranial pressure changes associated with childhood seizures. Dev Med Child Neurol 1978;20:561-9.
${ }^{35}$ Foltz EL. Hydrocephalus - the value of treatment. South Med J 1968;61:443-54.

${ }^{36}$ Portnoy HD, Croissant PD. A practical method for measuring hydrodynamics of cerebrospinal fluid. Surg Neurol 1976;5:273-7.

${ }^{37}$ Bell WE, McCormick WF. Increased intracranial pressure in children. Diagnosis and treatment. Vol 2. In: Major Problems in Clinical Pediatrics. Philadelphia: WB Saunders Co. 1978.

${ }^{38}$ Welch K. The emergency of hydrocephalus after ventricular hemorrhage and the estimation of intracranial pressure in infants. Am J Dis Child 1977;131:1203-4.

${ }^{39}$ Adams RD, Fisher CM, Hakim S, Ojemann RC, Sweet WH. Symptomatic occult hydrocephalus with "normal" cerebrospinal fluid pressure. $N$ Engl $J$ Med 1965;273:117-26.

${ }^{40}$ Martins AN. Resistance to drainage of cerebrospinal fluid. Clinical measurements and significance. $J$ Neurol Neurosurg Psychiatry 1973;36:313-8.

${ }^{41}$ Page LK, Bresman MJ, Lorenzo AV. Cerebrospinal fluid perfusion studies in childhood hydrocephalus. Surg Neurol 1973;1:317-20.

${ }^{42}$ Popich GA, Smith DW. Fontanels: range of normal size. J Pediatr 1972;54:786-90.

${ }^{43}$ Epstein F, Wald A, Hochwald GM. Intracranial pressure during compressive head wrapping in treatment of neonatal hydrocephalus. Pediatrics 1974;54:749-90.

${ }^{44}$ Hagberg B, Naglo A-S. The conservative management of infantile hydrocephalus. Acta Paediatr Scand 1972; 61:165-77.

${ }^{45}$ Smyth GE, Handersson WR. Observations on the cerebrospinal fluid pressure on simultaneous ventricular and lumbar punctures. J Neurol Psychiatry 1938; 1:226-37.

${ }^{46}$ Kaufmann GE, Clark K. Continuous simultaneous monitoring of intra-ventricular and cervical subarachnoid cerebrospinal fluid pressure to indicate development of cerebral or tonsillar herniation. J Neurosurg 1970; 33:145-50.

${ }^{47}$ Asch AJ, Myers GJ. Benign familial macrocephaly: Report of a family and review of the literature. Pediatrics 1976;57:535-9.

${ }^{48}$ Ellison PH. Re-evaluation of the approach to an enlarging head in infancy. Dev Med Child Neurol 1978;20:738-45.

${ }^{49}$ Day RE, Schutt WH. Normal children with large heads - benign familial megalencephaly. Arch Dis Child 1979;54:512-7.

${ }^{50}$ DeMyer W. Megaloencephaly in children. Neurology (Minneap) 1972;22:634-43.

${ }^{51}$ Moss ML. Functional anatomy of cranial synostosis. Child Brain 1975;1:22-3.

52 Renier D, Sainte-Rose C, Marchac D, Hirsch JF. Intracranial pressure in craniostenosis. $J$ Neurosurg 1982; 57:370-7. 